\title{
ABSTRACTS OF PUBLICATIONS
}

\section{COL I T HOUGHTON, late RAMC}

Houghton I T, Low J M, Lau J T F, Oh TE. An ethnic comparison of the sympathetic response to tracheal intubation. Anaesthesia 1993; 48: 965-968.

Abstract: Twenty seven male patients, five Europeans, 15 Chinese, and seven Nepalese, undergiong surgery with muscle relaxant anaesthesia, were studied to determine their sympathetic response to intubation. Plasma adrenaline and noradrenaline concentrations were measured in central venous blood by high performance liquid chromatography with colourmetric detection, before anaesthesia, at intubation, and for ten minutes after intubation. A significant increase in the mean noradrenaline concentration was found in the Chinese at one or two minutes after intubation which then decreased over five minutes. Similar increases in mean noradrenaline concentrations were found in the Europeans and Nepalese. The increases in mean adrenaline concentrations were less marked and occurred at intubation. Despite wide interindividual variation, the mean plasma catecholamine concentrations were comparable in the three groups, and it is possible, therefore, that there are no enthnic differences in the catecholamine responses to intubation in the ethnic groups studied.

\section{COL I T HOUGHTON, late RAMC}

Houghton I 'T, Chan K, WONG Y-C, Leung D H-Y, Aun CST. Biotransformation of pethidine: a comparative study of $24 \mathrm{~h}$ urine in three ethnic groups. Eur $J$ Drug Metab Pharmacokinet 1993; 18: 285-288.

\footnotetext{
Abstract: Twenty four hour urine was collected from 219 surgical patients of Caucasian, Chinese or Nepalese origin, following premedication with intramuscular pethidine $1 \mathrm{mg} / \mathrm{kg}$ body weight. The urine was analysed for pethidine, pethidinic acid, pethidinic acid conjugates, norpethidine, norpethidinic acid and norpethidinic acid conjugates. The mean proportion of the percentage of metabolites attributable to oxidative demethylation, hydrolysis and conjugation was almost identical in each ethnic group $(p<0.2)$ which suggests that there is no metabolic variability in the biotransformation of pethidine in Asians and Caucasians whose urine has not been acidified.
}

\author{
CAP'T M E LOVELL, RAMC(V), CAPT P \\ BRADSHAW, RAMC(V) \\ Lovell M E, Bradshaw P. Evaluation of the \\ conventional stretcher as support surface. Injury 1993; $24 \overrightarrow{\vec{F}}$ \\ (10): 660-661 \\ Project sponsored by the Royal Army Medical College, \\ Millbank, London, UK.
}

Abstract: The conventional wood and canvas stretcher was evaluated with regard to comfort and risk of pressure $i$ and ischaemic damage. Sixty subjects were evaluated and results were found to be similar to other support surfaces. A mean sacral interface pressure of $40.7 \mathrm{mmHg}$ was noted. Subjects found the stretchers cold and uncomfortable, particularly over the heels and lower back.

\section{LT COL T O JEFFERSON, RAMC}

JefFerson T O, Demichli V. Is Vaccination Against Hepatitis B Efficient? A Review of World Literature. $\frac{1}{\omega}$ Health Economics 1994; 3: 25-37.

Abstract: We report on the result of a study aimed assessing the variability of assumptions upon which economic models for the introduction of vaccination against Hepatitis B are based, the conclusions reache $\$$ and define a minimum set of methodological standar $\bar{b}$ upon which future economic studies on vaccines shoul : be based. We identified 116 published and unpublish

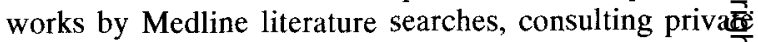
databases and corresponding with all authors and researchers active in economic evaluation of vaccines.

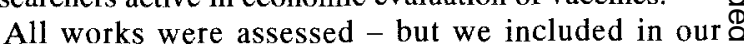
review only those which were original economic analyses $\vec{\overrightarrow{ }}$ (90 studies). Principal epidemiological and economic variables were extracted and compared where possible. Rough manipulations were carried out to make the data comparable. We found profound variability on the main parameters of the efficiency equation (disease incidence, costing methods, use of marginal theory, discounting and study timespan, sensitivity analysis and reporting methods). We also found inconsistencies in definition and study design in $38 \%$ of a subset of studies. Although we found scarce decision-making impact, we believe that due 3 to uncertain or unclear methodology, few studies reach $\delta$ valid conclusions. In future decisions may be based on biased evidence and scarce resources committed to윽 untested programmes. There is an urgent need to standardise study methods and define a common set of procedures. 
Journal of an Army Wife - From the Forties to the Eighties. A Creighton Williamson. Square One Publishers, 1991. Pp $9+211 . £ 12.95$. Illustrated. ISBN No: $1-872017-48-7$.

This is an interesting account of Forces life spanning over forty years. The author is extremely well qualified to make observations on the varied life styles that can be expected with frequent postings all over the world.

Audrey Creighton Williamson joined the Queen Alexandras Imperial Nursing Service in 1942 and became engaged to a Captain whilst en route to India during the Second World War. She remained in the Service until her discharge in 1945 when she concentrated her time, effort and energies on being an Army wife.

Each chapter reveals a new destination, a new home and new demands both domestically and socially to be overcome. Each new challenge is accepted with good grace and humour- sadly not always the case today. Many of the postings on which the author accompanied her husband no longer exist today and the reader cannot help but feel a sense of envy at the wonderful varied experiences described so graphically.

The only slight disappointment that I felt when reading the book was its title. I hope that the title will not prevent people reading this otherwise fascinating tale.

J J YOUNG

War Wounds of Limbs - Surgical Management. R M Coupland. Butterworth Heinemann, 1993, Pp v + 101. $£ 30.00$ Illustrated. ISBN 0750614919 .

War wounds of limbs is the most recent and welcome addition to the growing literature on war wounds and their management. Written by a universally recognised and admired expert, the book provides the military surgeon with clear and precise guidance on the management of war injured limbs. The advice given in each of the five concise chapters in based on the collected experience of the author and his surgical colleagues from the ICRC over the last twelve years. The extent of their collected experience is well outlined in one of two appendices data on the cause of injury in 12951 casualties, and the site of 27734 wounds is presented! The book is highly recommended and at $£ 30.00$ is a bargain.

\section{J M RYAN}

Childhood Cancer and Nuclear Installations. V Beral, E Roman and M Bobrow, Eds. British Medical Journal, 1993. Pp xi \& 453. £27.95. ISBN No: 0-7279-0815-4.

This book contains the main research articles of the past decade that have addressed the problem of clusters of leukaemia near nuclear plants.

It is a compilation of 55 original papers, abstracts, letters, editorials and government reports which have been published in various journals in the 10 years since 1983 when the Seascale cluster of childhood leukaemias was first reported in a television documentary.

The book is dedicated to the memory of the late Professor Martin John Gardner, best known for the
Gardner hypothesis which postulates that the father's 응 occupational exposure to ionizing radiation before conception increases the risk of childhood leukaemia and lymphoma. This case study is reproduced in full in chapter 19.

Other original studies conducted in the United Kingdom are reproduced in full in chapters $1-40$, extracts $\overline{\bar{p}}$ of government reports are presented in chapters 41-44 and $\vec{\nabla}$ letters and summaries by authors about investigations conducted elsewhere in the world are listed in chapters $\infty$ $45-55$

The book should appeal to epidemiologists and $\rightarrow$ statisticians and also to the interested general reader. $\vec{\omega}$ However the latter should be aware that there is no happy ending in this book. Over 10 years of research have posed $\vec{D}$ more questions than answers. Further studies have largely 3 failed to support the Gardner hypothesis and a decade? after its identification we are still unclear as to why the $\vec{f}$ cluster at Seascale is there.

R M JONES N

A Colour Atlas of Human Anatomy. R M H McMinn, R으 T Hutchings, J Peginton and PH Abrahams. Wolfe Publishing/Mosby-Year Book Europe, 1993. PP 35\%. C H/Back $£ 35.00$ P/Back $£ 19.95$. Illustrated ISBN (H/Bac 07234 1718-0 ISBN (P/Back) 07234 1915-9

This member of the widely known and acclaimed series $\overrightarrow{0}$ of colour atlases by Wolfe Medical Publishers is now in its 3rd edition. While still consisting mainly of the nos familiar excellent colour photographs, this new edition includes over 80 examples of magnetic resonance, CT af Ultrasound images designed to complement the photographs and allow side by side comparisons. Another new feature of the atlas is the inclusion of well executed $\stackrel{\mathbb{Q}}{2}$ line drawings alongside some of the more complex $\overrightarrow{\vec{a}}$ dissection photographs, improving orientation and 3 understanding. The book retains most of the more familiar $\bar{T}$ standard radiographs, angiograms, urograms and barium studies which were a noted feature of earlier editions. The text, as in all Wolfe atlases, is kept to a minimum so as not to detract from the visual impact of the illustrations. The atlas is strongly recommended to surgical trainees the paperback edition at under $£ 20.00$ is a snip.

J M RYAN

ABC of One to Seven. 3rd Ed. H B Valman. BMJ Publ Group, 1993. Pp 144. £8.95. Illustrated. ISBN No: $0 \frac{3}{6}$ 7279-0768-9.

This short book is a useful practical guide on common ailments and conditions of young children and is aimed at 을 vocational trainees, general practitioners and clinical $\supset$ medical officers.

A wide variety of topics is included and the advice on management is sound practice. Some subjects are touched o on only superficially but many of the more important $N$ issues in childhood illnesses, e.g. the management and N investigation of urinary tract infections, have been dealt ${ }_{\sigma}^{\omega}$ with in sufficient detail to ensure good treatment in 
general practice. The advice given on such conditions as sleep problems and enemesis is sound and uncontroversial.

The book also includes chapters on community aspects of child care including pre school services, the school health service and importantly child abuse. Medical audit is touched upon but not in detail as expected in such a short book.

Some diagrams are difficult to read, for instance, the outline of a DoH hospital nucleus key plan, but apart from such minor criticism the author's aims in this book have been achieved at a reasonable price.

J R MARSHALL

A Doctor's Experiences of Life. P. Dignan. The Pentland Press, 1994. £10.50. $\mathrm{Pp} \mathrm{x}+128$. Illustrated. ISBN No: 1 858211360.

A more appropriate title to this book would be The Autobiography of Patrick Dignan. Autobiographies should be written by those who have a claim to distinction or fame of some kind. This General Dignan does have in that he attained the pinnacle of his professional career as Director of Surgery in the RAMC although this feat is emulated by many officers in the RAMC on a regular basis.

The book is full of anecdotes which seem to have no impact and leave the reader expecting something which does not materialize. They are accounts of simple events which are within the experience of most doctors both in their formative years and in their professional careers within and without the Services. To give some examples:as a schoolboy footballer he injured the star player of the opposite team - a frequent event in any football game. In Singapore he was impressed by the expertise of an American surgeon doing vascular surgery. In Malaya he was awoken from a post prandial nap to assist a young lady deliver her baby. An RC padre was being driven by a Malayan soldier in the jungle without an escort. The car stopped and the driver got out for a pee. The padre was worried until the driver returned and explained his absence.

The book is written in a simple chatty style and reflects the gentility of the author. However it is unlikely to appeal to a wide spectrum of readers, and will be limited to General Dignan's immediate acquaintances and friends especially those in the Royal Army Medical Corps past and present.

At $\mathfrak{1 1 0 . 5 0}$ it is perhaps a little expensive compared to the many autobiographies currently being published.

J F WEBB

The Physiology and Medicine of Diving. 4th Edn. P B Bennett and D H Elliott. W B Saunders Co Ltd 1993, Pp $x+613 . £ 70.00$. ISBN No. $070201589 X$.

The developments which have taken place in commercial and recreational diving since the 3rd edition of this collection of reviews was published in 1983 are well summarised in the preface to the latest edition. Deep (i.e. greater than 50 metres depth) diving has become 3 more the province of remotely controlled diverless $\underset{\mathbb{D}}{\stackrel{D}{ }}$ vehicles and one-atmosphere diving systems, neither of $\Omega$ which involve human exposure to raised environmental pressure. In addition, a worldwide dearth of research funds has meant that in the past ten years military (including Royal Naval) and governmental research into of deep diving has virtually ceased, and further validation of 0 health and safety procedures for work down to 600 metres $\underline{0}$ (2000 feet) depth and below is now left to those oil companies which continue to need manned intervention $\mathbb{D}$ under pressure for such procedures as welding and emergency repairs to their offshore structures. The need is for such validation remains not only because the diverless $\overrightarrow{0}$ system which can perform any given task has not yet been developed but also because no diverless system is totally $\vec{\omega}$ dependable.

On the recreational diving front more and more people are diving for pleasure in temperate as well as tropical climates, and a minority of these individuals have adopted $\dot{\vec{A}}$ equipment and techniques such as mixed gas diving $\vec{t}$ which were hitherto the preserve of the commercial diver. The editors point out that further research into effective prevention of decompression sickness in this group is $\vec{\omega}$ essential; and the still unsolved question of how oxygen toxicity may be prevented will, when answered, provide additional benefit to sufferers from those medical an $c$ surgical conditions where hyperbaric oxygen has beê. shown to be therapeutically effective, albeit present limited in its effect by the human body's tolerance for this modality of treatment.

Numerous pathways for advancing man's safety whe under raised environmental pressure are detailed in the very concentrated volume whose every chapter supported by a comprehensive list of references. As a source of information for the hyperbaric scientist it is $\stackrel{\otimes}{\mathbb{D}}$ unsurpassed and fully deserves its place in the reference library, but at $£ 70.00$ it is probably outside the personal book budget of most Army doctors. Nevertheless selected chapters will repay careful study by those with an interest in diving and hyperbaric medicine. Chapter 10 on the management of diving accidents by Surgeon Commander D F Gorman, the Royal New Zealand Navy's current Director of Medical Services, is both brief and clear. This chapter dispenses with the old system of set diagnoses and uses a logical progression from accident to final treatment. There is a particularly useful discussion on what to do when the patient's consciousness is obtunded or when the acute brain syndrome has developed.

The chapter on otological and paranasal sinus problems in diving includes descriptions of alternobaric facial paralysis and recent studies of inner ear barotrauma - Dr $\mathrm{J}$ 윽 $C$ Farmer, the American author, also recommends not $\rightarrow$ operating on round window rupture caused by barotrauma until 24-48 hours observation with no improvement. This $N$ contrasts with Australian practice by such specialists as Freeman and Tonkin who operate early for this condition, $\mathrm{S}$ but the debate continues as to which is best. The chapter on thermal problems by Professor Sterba highlights the 0 important problem of heat loss into water at warm 
ambient temperatures as well as the less common but equally dangerous circumstance of heat stress when swimming or else performing work when wearing protective clothing. During his M.Sc. studies the reviewer came across three cases of superficial burns requiring hospital treatment in North Sea rig divers whose thermal suits were overpowered, but this particular hazard does not seem to be mentioned.

The disappointments in this volume are the misprints. "The first patient (should be patent) for the use of compressed air in subaqueous-tunnels ... was taken out ... in 1830 " on page 1; "pulmonar" for pulmonary on page 100; two figure number misprints on page 240 ; compression where decompression is meant on page 255 before the recommendation for Heimlich valves in managing pneumothoraces under raised ambient pressure; and finally an ambiguity caused by the identical type used to head tables and figures in chapter 18 leading to Table 18.3 referred to on page 521 having to be searched for on page 527 where it is located between Figures 18.11 and 18.12. But these are minor blemishes in a superb collection. A useful piece of practical information which the volume includes on page 253 is the telephone number of the Divers Alert Network (DAN) for Europe. When the reviewer was working at the Force Medical Office in HQ UNPROFOR Zagreb, the Head of Undersea Medicine at Alverstoke recommended that DAN should be contacted in the event of a recreational diving accident involving UNPROFOR personnel in former Yugoslavia. Journal readers proceeding thereunto - please note!
Molecular Biology of Digestive Disease $P$ Quirke Ed. BMJ Publishing Group 1994. Pp 116. UK £12.95 Overseas $£ 15.00$ ISBN No: 0727908278.

Whether or not we understand or like it, molecular biology is here to stay and will become increasingly important in Clinical Medicine. This short book is an excellent introduction to the subject, not least because the final chapter (almost one fifth of the entire text) is devoted to a comprehensive glossary of techniques - hybridisation, sequencing, polymerase chain reactions, restriction fragment length polymorphism, Northern and Southern blotting and many other "foreign" terms are clearly and concisely described. The ten other short chapters, each with extensive references, cover the main areas where molecular biology is already making a significant impact on the diagnosis or management of gastroenterological disease: various infections both bacterial (?Crohns disease) and viral (the hepatitides), colonic and gastric malignancy, growth factors, coeliac disease, single gene disorders, and gene therapy.

This concise, readable, inexpensive little book will be of value not only to junior doctors and students preparing for examinations, but also to practising gastroenterologists who need to be aware of the current state of knowledge in this growing field, and the exciting possibilities for future developments.

\section{J R BROWN}

\section{OBITUARIES}

Regimental Headquarters would welcome self written obituaries and when completed they should be forwarded to Regimental Secretary RHQ, RAMC, Keogh Barracks, Ash Vale, Aldershot, Hants GU12 5RQ. 